\title{
Summing up of Session Three
}

\author{
AXEL PERDRUP \\ Copenhagen
}

For more than two decades doctors have been able to diagnose and to cure nearly 100 per cent. of classical venereal disease with simple procedures, although not quite as simple as was stated by Mahony (1948): 'Everybody who can find a gluteal muscle and hit it can now cure syphilis'.

Recently the conception of venereal disease under its new and maybe less loaded name of sexually transmitted disease (STD) has been extended to include a number of genito-urinary infections, some of which are much more difficult to treat. Such difficulties may, I hope, be a challenge that induces a revival of the interest of the medical profession in the correct management of these diseases. The previous speakers have described the situation in developed and in developing countries with regard to medical manpower, equipment, investigation, teaching, and health education, using such adjectives as inadequate, poor, insufficient, or non-existent. This is so even in countries where the doctor:population ratio is now about 1:500 and where it would seem logical to assume that the classical venereal diseases would be quickly eradicated. The vast increase in the number of doctors has apparently had as little influence on the prevalence of venereal diseases as had the introduction first of sulphonamides and later of penicillin (Perdrup, 1961).

As abundance of doctors gives no solution to our problem, we rather need a change in the attitude of our profession towards our responsibility not only for the treatment of the individual patient but also for community health in which the management of important aspects of STD should be integrated.

It is now more and more in the modern style to attribute the so-called social diseases, which also comprise STD, to the structure of the community. If we in this Union are alert we may ensure that the increasing interest of new generations of doctors in the environment and in community health may also benefit the campaign against STD.

Presented at the 28th General Assembly of the IUVDT, Malta, April, 1975

Address for reprints: Prof. A. Perdrup, Hvidovre Hospital, Department of Dermatology and Venereology, Kettegárd Allé 30, KD 2650 Hvidovre, Denmark
The proper management of STD must of course be taught academically like any other discipline of medicine. Venereology must therefore have sufficient space in the curriculum of the medical schools and the teachers must necessarily belong to a group in which the management of STD is daily routine. Connected with the medical schools must necessarily be laboratories of sufficient size and standard to guarantee capacity and quality. This statement may sound banal, but it is called forth by the fact that it is difficult to recruit venereologists in many countries with an otherwise good supply of medical personnel. The situation is worse the more sophisticated the health system of the country and poor recruitment may be expected to lead to the degeneration of the specialty. Only in the U.K. and in Ireland is venereology a separate specialty; in other countries it is connected with another discipline, usually dermatology; and even where this connection has a long tradition there is often a tendency to neglect venereology.

In the developing countries the outlook is still more gloomy because most components of the medical structure and infrastructure are lacking. The health problems are overwhelming and STD is given low priority. Yet the venereal disease situation in such countries is so grave that they need prompt action. I am not too worried over placing responsibility in the hands of auxiliaries (Arya, 1975), because we have a good precedent proving that amazing results can be achieved if there are high standards at headquarters, with a limited number of specialists leading teams with a great number of well-informed and motivated auxiliaries, and plenty of enthusiasm. I refer to the WHO campaign against yaws in the late forties and early fifties. It was so effective that you now hear complaints about the loss of acquired immunity against venereal syphilis (Király, 1973).

Of course the management of STD is more complex than the management of yaws. The first step must be the establishment of demonstration and training centres from which methodology and knowledge can spread. Besides this, the control must be based on simple and practical actions where 
mobile teams collect mass information, and carry out mass examination and mass treatment. The mass follow-up and the daily routine should be dealt with by auxiliaries acquainted with the locality and periodically supervised from the centre where they have been trained.

The WHO is this year demonstrating an increased interest in STD and it is to be hoped that it may once more succeed in using a modified model of its anti-yaws campaign.

In our anxiety to assist the developing countries with whatever aid we can afford to send them, let us not forget that money spent on promising research on the immunity of micro-organisms and of their human hosts, carried out in our home research centres, may give results that are much more profitable to developed as well as to developing countries.

\section{References}

ARYA, O. P. (1976) Brit. F. vener. Dis., 52, 116

Delune, H. (1976) Ibid., 52, 107

KIRALY, K. (1973) 'Immunoallergological Aspects of Syphilis'. WHO/VDT/RES/73.304

Knox, J. M. (1976) Brit. F. vener. Dis., 52, 105

MahoNy, J. F. (1948) Personal communication

PERDRUP, A. (1961) Brit. F. vener. Dis., 37, 115

Schmidt, H. (1976) Ibid., 52, 113

TowPIK, J. (1976) Ibid., 52, 110 